\title{
Impact of Nutritional Assessment on Long-Term Outcomes in Patients with Carotid Artery Stenting
}

\author{
Muhammed Demir ${ }^{1}$ and Mehmet Ozbek ${ }^{1}$ \\ ${ }^{1}$ Dicle University Medical Faculty
}

June 20, 2021

\begin{abstract}
Objective: Malnutrition is associated with poor clinical outcomes in many diseases. The Controlling Nutritional Status (CONUT) is an objective index used for evaluating nutritional status of hospitalized patients. The aim of this study was to investigate the relationship between malnutrition assessed by CONUT score and the prognosis in patients undergoing carotid artery stenting (CAS). Methods: The study included 170 patients who underwent CAS due to symptomatic or asymptomatic severe carotid artery stenosis. Median follow-up period was 50 (interquartile range [IQR], 41-60) months. Patients were divided into two groups according to the CONUT score: (i) normal nutrition $(<2)$ and (ii) malnutrition ([?]2). Primary endpoint was accepted as MACE (major adverse cardiac events) including all-cause death and ischemic stroke. Results:The prevalence of MACE was significantly higher in the malnutrition group $(\mathrm{p}=0.001)$. Kaplan Meier analysis showed lower survival rates in the malnutrition group $(\log \operatorname{rank}=9.36, \mathrm{p}=0.002$; Figure 4 ). In multivariate logistic regression analysis, age and CONUT score were independent predictors of all-cause death and stroke after adjustment for confounding factors, respectively, (OR: 1.058, 95\% CI: 1.013-1.105, $\mathrm{p}=0.011$, OR: $1.318,95 \%$ CI: 1.017-1.881, $\mathrm{p}=0.039)$. Conclusion: Higher CONUT scores were associated with adverse outcomes in patients with CAS. Malnutrition assessed by the CONUT score may provide valuable prognostic information in patients with CAS.
\end{abstract}

\section{Introduction}

Stroke is a leading cause of disability and death worldwide. Atherosclerotic narrowing of the extracranial carotid arteries is responsible for approximately one-fifth of all strokes (1). There are two main interventional treatment methods in symptomatic or asymptomatic high-grade carotid artery stenosis: carotid artery stenting (CAS) and carotid endarterectomy $(2,3)$. Although there is sufficient evidence on the long-term outcomes of patients after CAS, potential risk factors affecting the long-term course of the disease have not yet been studied sufficiently $(4,5)$.

Comorbid diseases accompanying severe CAS affect the long-term outcomes of the disease. Although risk factors showing long-term consequences such as diffuse proliferative hyperplasia after CAS, low high-density lipoprotein cholesterol level, diabetes mellitus, low body mass index (BMI), and contralateral carotid artery occlusion have so far been identified, a detailed risk assessment has not yet been performed (6-10).

Malnutrition is associated with adverse outcomes in many diseases (11-12). The Controlling Nutritional Status (CONUT) score is an objective index widely used for evaluating nutritional status of individuals. The CONUT score is calculated based on serum albumin level, total cholesterol level, and total lymphocyte count and it can assess protein reserves, calorie deficit, and immune response (13). Clinical significance of malnutrition as assessed by the CONUT score has been demonstrated in patients with hypertension, acute coronary syndrome (ACS), and heart failure (14-16).

Although the CONUT score is a practical, applicable, scoring system with a prognostic value, its clinical significance has not yet been elucidated in CAS patients. The aim of this study was to investigate the 
relationship between malnutrition assessed by CONUT score and prognosis in patients undergoing CAS.

\section{Methods}

\section{Study Population}

The study was designed as a single-center, retrospective study and included 170 patients who underwent CAS due to symptomatic or asymptomatic severe carotid artery stenosis in Dicle University Medical School Hospital between December 2011 and December 2020. Patients with hematological diseases, systemic inflammatory diseases, malignancies, active infectious diseases, end-stage kidney and liver diseases, and a history of thrombolytic therapy within the last 24 hours were excluded from the study. The study was conducted in accordance with the Helsinki Declaration and the study protocol was approved by the local ethics committee. The experimental protocols and the process for obtaining informed consent were approved by the appropriate institutional review committee.

\section{Definitions}

A detailed medical history was obtained from all patients at the time of admission. Hypertension was defined as a systolic blood pressure (SBP) of [?]140 $\mathrm{mmHg}$ or a diastolic blood pressure (DBP) of [?]90 $\mathrm{mmHg}$ or using antihypertensive medication. Diabetes mellitus (DM) was defined as a fasting glucose level of [?]126 $\mathrm{mg} / \mathrm{dl}$ or use of antidiabetic agents or HbA1c $>7 \%$. Dyslipidemia was defined as a total cholesterol level of $>200 \mathrm{mg} / \mathrm{dl}$ or low-density lipoprotein level (LDL) of $>130 \mathrm{mg} / \mathrm{dL}$. Smoking was defined as current cigarette smoking. Coronary artery disease (CAD) was defined as $>50 \%$ narrowing in at least one coronary artery. Peripheral artery disease (PAD) was defined as $>50 \%$ stenosis in peripheral arteries. Transient ischemic attack (TIA) was defined based on the 2009 American Heart Association/American Stroke Association (AHA/ASA) guidelines as a transient episode of neurological dysfunction in the spinal cord, retina, and focal brain without acute infarction. Ischemic stroke was defined as an infarction causing neurological dysfunction in the focal brain, spinal cord, and retina lasting more than 24 hours.

Blood Samples and Nutritional Indexes

Hematological and biochemical tests were conducted on the venous blood samples obtained from each patient immediately before routine carotid angiography. Determination of the counts and types of shaped elements of blood was performed for each patient using an automated hematological analyzer (Abbott Cell-Dyn 3700; Abbott Laboratory, Abbott Park, Illinois, USA). Biochemical measurements were performed using the standard methods. The CONUT score is calculated based on three parameters: serum albumin level, total cholesterol level, and total lymphocyte count (Table 1). Patients were divided into two groups according to the CONUT score: (i) normal nutrition $(<2)$ and (ii) malnutrition ([?]2). Prognostic nutritional index (PNI) was calculated using the following formula: $10 \mathrm{x}$ serum albumin value $(\mathrm{g} / \mathrm{dL})+0.005 \mathrm{x}$ total lymphocyte count in the peripheral blood $\left(\right.$ per $\mathrm{mm}^{3}$ ). Patients were divided into two groups based on a PNI cutoff value of 40: (i) low PNI ([?]40) and (ii) high PNI (>40).

\section{MACE and follow-up}

Primary endpoint was accepted as MACE (major adverse cardiac events) including all-cause death and ischemic stroke. The follow-up period was defined as the time from the moment of admission to our clinic for angiography to death due to any cause or to the last clinical visit. Data on patients' death were accessed by telephone interviews or were retrieved from the civil registration records.

Statistical analysis

Data were analyzed using SPSS for Windows version 25.0 (Armonk, NY: IBM Corp.). Normal distribution of data was analyzed using Kolmogorov-Smirnov test. Categorical variables were expressed as percentages (\%) and were compared using Chi-square test. Continuous variables with normal distribution were expressed as mean \pm standard deviation (SD) and were compared using Student's t-test. Continuous variables with nonnormal distribution were expressed as median $\left(25^{\text {th }}-75^{\text {th }}\right.$ percentile) and were compared using MannWhitney $\mathrm{U}$ test. Independent predictors of mortality were determined using univariate and multivariate 
logistic regression analysis and the results were expressed with odds ratio (OR) and $95 \%$ confidence interval (CI). The optimum PNI and CONUT score cutoff values for the prediction of mortality were determined using receiver operating characteristic (ROC) curve analysis. Correlations were analyzed using Spearman's correlation coefficient. Survival analysis was performed using Kaplan-Meier analysis. A $p$ value of $<0.05$ was considered significant.

\section{Results}

The study included 170 patients, comprising 105 (61.8\%) men and 65 women (38.2\%) with a mean age of $68.27 \pm 10.23$ years. Median follow-up period was 50 (interquartile range [IQR]: 41-60.25) months. Patients were divided into two groups according to the CONUT score: (i) normal nutrition $(<2)$ and (ii) malnutrition ([?]2). Clinical characteristics of both groups are shown in Table 2. The mortality rate and the neutrophil-to-lymphocyte ratio (NLR) were significantly higher and the PNI scores were significantly lower in the malnutrition group compared to the normal nutrition group $(p=0.001, p<0.001$, and $p<0.001$, respectively). Table 3 presents a comparison of baseline hematological and biochemical parameters of both groups. Significant differences were found between the two groups with regard to serum hemoglobin, hematocrit, lymphocyte, glucose, creatinine, albumin, total cholesterol, LDL, high-density lipoprotein (HDL), thyroid stimulating hormone (TSH), and C-reactive protein (CRP) levels.

In univariate logistic regression analysis, age, PNI, and CONUT score were found to be independent predictors of all-cause death and stroke (Odds Ratio [OR]: 1.061, 95\% CI: 1.020-1.103, $p=0.003$, OR: 0.915, 95\% CI: $0.864-0.970, p=0.003$, OR: $1.134,95 \%$ CI: $1.130-1.590, p=0.001)$. In multivariate logistic regression analysis, age and CONUT score were independent predictors of all-cause death and stroke, respectively (OR: 1.058, 95\% CI: $1.013-1.105, p=0.011$, OR: $1.318,95 \%$ CI: $1.017-1.881, p=0.039$ ) (Table 4).

At a cutoff value of 1.5, the CONUT score predicted long-term all-cause death and stroke with a sensitivity of $66 \%$ and a specificity of $62 \%$ (ROC area under curve [AUC]: 0.644, 95\% CI: 0.541-0.747; Figure 1). At a cutoff value of 46 , PNI predicted long-term all-cause death and stroke with a sensitivity of $65 \%$ and a specificity of $57 \%$ (AUC: $0.655,95 \%$ CI: 0.560-0.749; Figure 2). A negative correlation was observed between the CONUT score and PNI ( $\mathrm{r}=-0.716, p<0.001$; Figure 3$)$. Kaplan Meier analysis showed lower survival rates in the malnutrition group ( $\log$ rank $=9.36, p=0.002$; Figure 4$)$ and in the group with a low PNI score $([?] 40)(\log \operatorname{rank}=14.98, p<0.001 ;$ Figure 5$)$.

\section{Discussion}

The present study investigated the long-term prognostic value of malnutrition assessed by the CONUT score in CAS patients and the results indicated a higher prevalence of all-cause death and stroke in malnourished patients compared to patients with normal nutrition.

The CONUT score was first described by Ignacio de Ulı'barri et al as an objective parameter reflecting malnutrition in hospitalized patients (13). In recent studies, the association of the CONUT score with clinical poor outcomes has been demonstrated in various cardiovascular diseases. Takahashi et al. reported that high CONUT score was associated with adverse outcomes in patients with ACS and also showed its prognostic value in ACS patients (15). Nochioka et al. showed that malnutrition assessed by the CONUT score was associated with adverse cardiac events in patients with chronic heart failure (17). Kunimura et al. demonstrated that the combined use of BMI and CONUT score in stable CAD was associated with MACE (18). In some other studies, the CONUT score was shown to be an independent strong predictor of adverse cardiovascular events and foot events in PAD patients (19). Additionally, it was also reported to be associated with increased prevalence of all-cause death in patients with ST elevation myocardial infarction (STEMI) (20).

To date, numerous nutritional indicators such as serum albumin, total cholesterol, Mini Nutritional Assessment (MNA), Subjective Global Assessment (SGA), and Geriatric Nutritional Risk Index (GNRI) have been reported (21-23). Of these, MNA and SGA are dependent on the physician's subjective observations. Nevertheless, an evaluation performed with only one nutritional indicator may be affected by various factors 
and may not provide sufficient information. Therefore, in this study, we used PNI in addition to the CONUT score. PNI, which is calculated on serum albumin level and total lymphocyte count, is an objective nutritional indicator reflecting the immune-nutritional status of individuals. Decreased albumin and lymphocyte response in acute diseases reflect poor immune-nutritional status. On the other hand, PNI is mainly used as a parameter reflecting the immune-nutritional status of patients planned for gastrointestinal surgery to assess the risk of perioperative surgery $(24,25)$. In our study, a PNI score of [?]40 was associated with a shorter survival time.

In the literature, CAS patients have been evaluated with biochemical parameters as well. Of these, NLR has been shown to be associated with in-stent restenosis in CAS patients (26). Additionally, CRP and B-type natriuretic peptide (BNP) have been demonstrated to have a prognostic value in CAS patients undergoing carotid surgery (27).

Both the studies in the literature and our study indicated that malnutrition is associated with mortality. Accordingly, the CONUT score, which is an objective and easily applicable scoring system, can be a useful nutritional indicator in predicting adverse events in CAS patients and, as a novel indicator, can contribute to the prediction of adverse events such as long-term mortality and stroke in the CAS patients, in addition to traditional parameters.

The study had several limitations. First, it was a single-center retrospective study and had a relatively small sample size. Second, the CONUT scores were not assessed after hospital discharge and thus the effect of changes in post-discharge CONUT scores on clinical outcomes could not be evaluated. Third, malnutrition was assessed only by using the CONUT score and PNI, and other nutritional indicators such as MNA, SGA, and GNRI were not used.

In conclusion, malnutrition assessed by the CONUT score was associated with poor prognosis in patients with CAS. The CONUT score is a useful tool for risk stratification of patients with CAS.

\section{Acknowledgments}

The authors wish to thank Lezgin Dursun, who worked as a researcher at the School of Medicine of Dicle University for his data assistance.

\section{References}

[1] Mozaffarian D, Benjamin EJ, Go AS, Arnett DK, Blaha MJ, Cushman M et al. American Heart Association Statistics Committee; Stroke Statistics Subcommittee. Executive Summary: Heart Disease and Stroke Statistics-2016 Update: A Report From the American Heart Association. Circulation. $2016 ; 133: 447-54$. https://doi: 10.1161/CIR.0000000000000366.

[2] Sacco RL, Adams R, Albers G, et al. Guidelines for prevention of stroke in patients with ischemic stroke or transient ischemic attack: a statement for healthcare professionals from the American Heart Association/American Stroke Association Council on Stroke: co-sponsored by the Council on Cardiovascular Radiology and Intervention: the American Academy of Neurology affirms the value of this guideline. Circulation 2006;113:e409-e449. https://doi: 10.1161/01.STR.0000199147.30016.74.

[3] Barnett HJM, Taylor DW, Haynes RB, Sackett DL, Peerless SJ, Ferguson GG, et al. Beneficial effect of carotid endarterectomy in symptomatic patients with high-grade carotid stenosis. N Engl J Med. 1991;325:445-53. https://doi: 10.1056/NEJM199108153250701.

[4] Gurm HS, Yadav JS, Fayad P, Katzen BT, Mishkel GJ, Bajwa TK, et al; SAPPHIRE Investigators. Longterm results of carotid stenting versus endarterectomy in high-risk patients. N Engl J Med. 2008;358:1572-79. https:// doi: 10.1056/NEJMoa0708028.

[5] Yadav JS, Wholey MH, Kuntz RE, Fayad P, Katzen BT, Mishkel GJ, et al. Stenting and Angioplasty with Protection in Patients at High Risk for Endarterectomy Investigators. Protected carotid-artery stenting 
versus endarterectomy in high-risk patients. N Engl J Med. 2004;351:1493-1501.https:// doi: 10.1056/NEJMoa040127

[6] Yuo TH, Goodney PP, Powell RJ, Cronenwett JL. "Medical high risk" designation is not associated with survival after carotid artery stenting. J Vasc Surg. 2008;47:356-62. https:// doi: 10.1016/j.jvs.2007.10.046.

[7] Lal BK, Kaperonis EA, Cuadra S, Kapadia I, Hobson RW, Jr. Patterns of in-stent restenosis after carotid artery stenting: classification and implications for long-term outcome. J Vasc Surg. 2007;46:833-40. https:// doi: $10.1016 /$ j.jvs.2007.07.022.

[8] Niessner A, Hofmann R, Kypta A, Steinwender C, Kerschner K, Kammler J, et al. Low high-density lipoprotein cholesterol predicts cardiovascular events after carotid stenting: a long-term survey. J Thromb Haemost. 2007;5:950-54. https://doi: 10.1111/j.1538-7836.2007.02451.x.

[9] Gurm HS, Fathi R, Kapadia SR, Abou-Chebl A, Vivek DP, Bajzer C, et al. Impact of body mass index on outcome in patients undergoing carotid stenting. Am J Cardiol. 2005;96:1743-45. https:// doi: 10.1016/j.amjcard.2005.07.100.

[10] Keldahl ML, Park MS, Garcia-Toca M, Wang CH, Kibbe MR, Rodriguez HE, et al. Does a contralateral carotid occlusion adversely impact carotid artery stenting outcomes? Ann Vasc Surg. 2012;26:40-5. https:// doi: 10.1016/j.avsg.2011.07.005.

[11] Datema FR, Ferrier MB, Baatenburg de Jong RJ. Impact of severe malnutrition on short-term mortality and overall survival in head and neck cancer. Oral Oncol. 2011;47:910-14. https:// doi: 10.1016/j.oraloncology.2011.06.510.

[12] Horwich TB, Kalantar-Zadeh K, MacLellan RW, Fonarow GC. Albumin levels predict survival in patients with systolic heart failure. Am Heart J. 2008;155:883-89. https:// doi: 10.1016/j.ahj.2007.11.043.

[13] Ignacio de Ulibarri J, Gonzalez-Madrono A, de Villar NG, Gonzalez P, Gonzalez B, Mancha A, et al. CONUT: a tool for controlling nutritional status. First validation in a hospital population. Nutr Hosp. $2005 ; 20: 38-45$

[14] Sun X, Luo L, Zhao X, Ye P. Controlling Nutritional Status (CONUT) score as a predictor of all-cause mortality in elderly hypertensive patients: a prospective follow-up study. BMJ Open. 2017;7(9):e015649. https://doi: 10.1136/bmjopen-2016-015649.

[15] Takahashi T, Watanabe T, Otaki Y, Kato S, Tamura H, Nishiyama S, et al. Prognostic significance of the controlling nutritional (CONUT) score in patients with acute coronary syndrome. Heart Vessels. 2021 Feb 4. https://doi: 10.1007/s00380-021-01792-4.

[16] Nishi I, Seo Y, Hamada-Harimura Y, Sato K, Sai S, Yamamoto M, et al. Nutritional screening based on the controlling nutritional status (CONUT) score at the time of admission is useful for long-term prognostic prediction in patients with heart failure requiring hospitalization. Heart Vessels. 2017;32:1337-49. https://doi: 10.1007/s00380-017-1001-8.

[17] Nochioka K, Sakata Y, Takahashi J, Miyata S, Miura M, Takada T, et al. Prognostic impact of nutritional status in asymptomatic patients with cardiac diseases: a report from the CHART-2 Study. Circ J. 2013;77:2318-26. https:// doi: 10.1253/circj.cj-13-0127.

[18] Kunimura A, Ishii H, Uetani T, Aoki T, Harada K, Hirayama K, et al. Impact of nutritional assessment and body mass index on cardiovascular outcomes in patients with stable coronary artery disease. Int J Cardiol. 2017; 230:653-58. https://doi:10.1016/j.ijcard.2017.01. 008.

[19] Yokoyama M, Watanabe T, Otaki Y, Watanabe K, Toshima T, Sugai T, et al. Impact of Objective malnutrition status on the clinical outcomes in patients with peripheral artery disease following endovascular therapy. Circ J. 2018;82:847-56. https://doi.org/10.1253/circj.CJ-17-0731. 
[20] Basta G, Chatzianagnostou K, Paradossi U, Botto N, Del Turco S, Taddei A, et al. The prognostic impact of objective nutritional indices in elderly patients with ST-elevation myocardial infarction undergoing primary coronary intervention. Int J Cardiol. 2016;221:987-92. https:// doi: 10.1016/j.ijcard.2016.07.039.

[21] Guigoz Y, Vellas B, Garry PJ. Assessing the nutritional status of the elderly: the mini nutritional assessment as part of the geriatric evaluation. Nutr Rev. 1996;54:59-65. https:// doi: 10.1111/j.17534887.1996.tb03793.x.

[22] Detsky AS, McLaughlin JR, Baker JP, Johnston N, Whittaker S, Mendelson RA, et al. What is subjective global assessment of nutritional status? J Parenter Enteral Nutr. 1987;11:8-13. https:// doi: $10.1177 / 014860718701100108$.

[23] Bouillanne O, Morineau G, Dupont C, Coulombel I, Vincent JP, Nicolis I, et al. Geriatric Nutritional Risk Index: a new index for evaluating at-risk elderly medical patients. Am J Clin Nutr. 2005;82:777-83. https:// doi: 10.1093/ajcn/82.4.777.

[24] Gupta D, Lis CG. Pretreatment serum albumin as a predictor of cancer survival: a systematic review of the epidemiological literature. Nutr J. 2010;9:69. https:// doi: 10.1186/1475-2891-9-69.

[25] Yang L, Xia L, Wang Y, et al. Low prognostic nutritional index (PNI) predicts unfavorable distant metastasis-free survival in nasopharyngeal carcinoma: a propensity score-matched analysis. PLoS One. 2016; 11(7): e0158853. https:// doi.org/10.1371/journal.pone.0158853.

[26] Shen H, Dai Z, Wang M. Preprocedural neutrophil to albumin ratio predicts in-stent restenosis following carotid angioplasty and stenting. J Stroke Cerebrovasc Dis. 2019;28:2442-47. https:// doi: 10.1016/j.jstrokecerebrovasdis.2019.06.027.

[27] Stone PA, Thompson SN, Khan M, et al. The impact of biochemical markers on major adverse cardiovascular events and contralateral carotid artery stenosis progression following carotid interventions. Ann Vasc Surg. 2017;38:144-50. https://doi: 10.1016/j.avsg.2016.08.004.

Competing Interests: The authors have nothing to disclose.

Acknowledgements: The authors wish to thank Lezgin Dursun, who worked as a researcher at the School of Medicine of Dicle University for his data assistance.

Funding: None

Table 1. Severity of malnutrition assessed by CONUT score

\begin{tabular}{lllll}
\hline Parameter & Severity & Severity & Severity & Severity \\
\hline & Normal & Mild & Moderate & Severe \\
Serum albumin $(\mathrm{g} / \mathrm{dl})$ & {$[?] 3.5$} & $3-3.49$ & $2.5-2.99$ & $<2.5$ \\
Score & 0 & 2 & 4 & 6 \\
Total lymphocytes $(/ \mu \mathrm{L})$ & {$[?] 1600$} & $1200-1599$ & $800-1199$ & $<800$ \\
Score & 0 & 1 & 2 & 3 \\
Total cholesterol $(\mathrm{mg} / \mathrm{dl})$ & {$[?] 180$} & $140-179$ & $100-139$ & $<100$ \\
Score & 0 & 1 & 2 & 3 \\
Total CONUT score & $0-1$ & $2-4$ & $5-8$ & $9-12$ \\
\hline
\end{tabular}

CONUT: Controlling Nutritional Status

Table 2. Clinical characteristics 


\begin{tabular}{|c|c|c|c|c|}
\hline & Total $\mathbf{N}=\mathbf{1 7 0}$ & $\begin{array}{l}\text { CONUT }<2 \\
\mathrm{~N}=93\end{array}$ & $\begin{array}{l}\text { CONUT [?]2 } \\
\mathrm{N}=77\end{array}$ & $\mathrm{p}$ \\
\hline$\overline{\text { Age (Years) }}$ & $68.27 \pm 10.23$ & $66.17 \pm 10.23$ & $70.81 \pm 9.70$ & 0.003 \\
\hline Male & $105(61.8 \%)$ & $55(59.1 \%)$ & $50(64.9 \%)$ & 0.439 \\
\hline $\begin{array}{l}\text { Follow-up period } \\
\text { (Months) }\end{array}$ & $50(41-60.25)$ & $52(42.5-59)$ & $48(37-64.5)$ & 0.306 \\
\hline Mortality & $40(23.5 \%)$ & $13(14 \%)$ & $27(35.1 \%)$ & 0.001 \\
\hline $\begin{array}{l}\text { New-onset stroke } \\
\text { (Follow-up } \\
\text { period) }\end{array}$ & $4(2.4 \%)$ & $1(1.1 \%)$ & $3(3.9 \%)$ & $0.330^{*}$ \\
\hline MACE & $44(25.9 \%)$ & $15(16.1 \%)$ & $29(37.7 \%)$ & 0.001 \\
\hline Hypertension & $126(74.1 \%)$ & $67(72 \%)$ & $59(76.6 \%)$ & 0.497 \\
\hline Diabetes mellitus & $63(37.1 \%)$ & $33(35.5 \%)$ & $30(39 \%)$ & 0.640 \\
\hline Dyslipidemia & $130(76.5 \%)$ & $76(81.7 \%)$ & $54(70.1 \%)$ & 0.076 \\
\hline Active smoking & $82(48.2 \%)$ & $48(51.6 \%)$ & $34(44.2 \%)$ & 0.333 \\
\hline CAD & $104(61.2 \%)$ & $61(65.6 \%)$ & $43(55.8 \%)$ & 0.194 \\
\hline PAD & $7(4.1 \%)$ & $4(4.3 \%)$ & $3(3.9 \%)$ & 0.652 \\
\hline Stroke & $66(38.8 \%)$ & $31(33.3 \%)$ & $35(45.5 \%)$ & 0.106 \\
\hline $\begin{array}{l}\text { Transient } \\
\text { ischemic attack }\end{array}$ & $73(42.9 \%)$ & $39(41.9 \%)$ & $34(44.2 \%)$ & 0.771 \\
\hline Amaurosis fugax & $13(7.6 \%)$ & $8(8.6 \%)$ & $5(6.5 \%)$ & 0.607 \\
\hline $\begin{array}{l}\text { Rhythm Sinus } \\
\text { rhythm Atrium } \\
\text { fibrillation }\end{array}$ & $\begin{array}{l}161(94.7 \%) 9 \\
(5.3 \%)\end{array}$ & $87(93.5 \%) 6(6.5 \%)$ & $74(96.1 \%) 3(3.9 \%)$ & 0.459 \\
\hline $\begin{array}{l}\text { Stented vessel Right } \\
\text { Carotid Artery }\end{array}$ & $78(45.9 \%)$ & $49(52.7 \%)$ & $29(37.7 \%)$ & 0.050 \\
\hline $\begin{array}{l}\text { Left Carotid } \\
\text { Artery }\end{array}$ & $102(60 \%)$ & $50(53.8 \%)$ & $52(67.5 \%)$ & 0.068 \\
\hline Left carotid stenosis & $55(32.4 \%) 5(2.9 \%)$ & $36(38.7 \%) 2(2.2 \%)$ & $19(24.7 \%) 3(3.9 \%)$ & $0.218^{*}$ \\
\hline $\begin{array}{l}0-50 \% 50-69 \% \\
70-89 \% 90-100 \%\end{array}$ & $\begin{array}{l}43(25.3 \%) 67 \\
(39.4 \%)\end{array}$ & $\begin{array}{l}23(24.7 \%) 32 \\
(34.4 \%)\end{array}$ & $20(26 \%) 35(45.5 \%)$ & \\
\hline $\begin{array}{l}\text { Right carotid } \\
\text { stenosis } 0-50 \% \\
50-69 \% 70-89 \% \\
90-100 \%\end{array}$ & $\begin{array}{l}89(52.4 \%) 3(1.8 \%) \\
42(24.7 \%) 36 \\
(21.2 \%)\end{array}$ & $\begin{array}{l}42(45.2 .7 \%) 3 \\
(3.2 \%) 29(31.2 \%) \\
19(20.4 \%)\end{array}$ & $\begin{array}{l}47(61 \%) 0(0 \%) 13 \\
(16.9 \%) 17(22.1 \%)\end{array}$ & $0.040^{*}$ \\
\hline ASA/clopidogrel & $170(100 \%)$ & $93(100 \%)$ & $77(100 \%)$ & $* *$ \\
\hline ACEI/ARB & $112(65.9 \%)$ & $61(65.6 \%)$ & $51(66.2 \%)$ & 0.930 \\
\hline Beta-blocker & $118(69.4 \%)$ & $61(65.6 \%)$ & $57(74 \%)$ & 0.235 \\
\hline Statins & $162(95.3 \%)$ & $89(95.7 \%)$ & $73(94.8 \%)$ & 0.784 \\
\hline $\begin{array}{l}\text { Body mass index, } \\
\mathrm{kg} / \mathrm{m}^{2}\end{array}$ & $25.22(24.08-27.2)$ & $25(24.03-26.94)$ & $\begin{array}{l}25.40 \\
(24.21-27.45)\end{array}$ & 0.398 \\
\hline $\begin{array}{l}\text { Ejection fraction } \\
(\%)\end{array}$ & $60(60-60)$ & $60(55-60)$ & $60(60-60)$ & 0.231 \\
\hline SBP mmHg DBP & $130(120-137)$ & $130(120-136)$ & $130(120-138)$ & 0.5390 .752 \\
\hline $\mathrm{mmHg}$ & $76.5(70-80)$ & $76(70-80)$ & $78(70-80)$ & \\
\hline $\begin{array}{l}\text { Prognostic } \\
\text { nutritional index }\end{array}$ & $46.35 \pm 6.59$ & $50.12 \pm 4.57$ & $41.81 \pm 5.76$ & $<0.001$ \\
\hline $\begin{array}{l}\text { Neutrophil to } \\
\text { lymphocyte ratio }\end{array}$ & $2.53(1.93-3.46)$ & $2.25(1.81-2.83)$ & $2.96(2.25-4.9)$ & $<0.001$ \\
\hline
\end{tabular}


Data are expressed as mean \pm standard deviation (SD), frequencies (percentages) or as median (interquartile range) as appropriate. ${ }^{*}$ Fisher's Exact Test. ${ }^{* *}$ No statistics were computed because ASA and clopidogrel are constant. MACE: Major adverse cardiac events, CAD: Coronary artery disease, PAD: Peripheral artery disease, ASA: Acetylsalicylic acid, ACEI: Angiotensin-converting enzyme inhibitor, ARB: Angiotensin receptor blocker, SBP: Systolic blood pressure, DBP: Diastolic blood pressure

Table 3. Baseline hematological and biochemical parameters

\begin{tabular}{|c|c|c|c|c|}
\hline & Total $\mathbf{N}=\mathbf{1 7 0}$ & $\begin{array}{l}\text { CONUT }<2 \\
\mathbf{N}=93\end{array}$ & $\begin{array}{l}\text { CONUT [?]2 } \\
\mathrm{N}=77\end{array}$ & $\mathrm{p}$ \\
\hline $\begin{array}{l}\text { White blood cell } \\
\text { count }\left(\times 10^{6} \mu \mathrm{L}\right)\end{array}$ & $8652 \pm 2384$ & $8628 \pm 2084$ & $8681 \pm 2717$ & 0.887 \\
\hline $\begin{array}{l}\text { Hemoglobin } \\
(\mathrm{g} / \mathrm{dl})\end{array}$ & $13.16 \pm 1.77$ & $13.61 \pm 1.55$ & $12.61 \pm 1.88$ & $<0.001$ \\
\hline Hematocrit (\%) & $40.58 \pm 4.94$ & $42.12 \pm 4.48$ & $38.71 \pm 4.86$ & $<0.001$ \\
\hline $\begin{array}{l}\text { Lymphocytes }(\times \\
\left.10^{6} \mu \mathrm{L}\right)\end{array}$ & $2128 \pm 899$ & $2347 \pm 738$ & $1863 \pm 1005$ & $<0.001$ \\
\hline $\begin{array}{l}\text { Neutrophils }(\times \\
\left.10^{6} \mu \mathrm{L}\right)\end{array}$ & $5613 \pm 2073$ & $5397 \pm 1778$ & $5873 \pm 2367$ & 0.136 \\
\hline Uric acid & $5.72 \pm 1.85$ & $5.65 \pm 1.8$ & $5.81 \pm 1.93$ & 0.579 \\
\hline Glucose $(\mathrm{mg} / \mathrm{dl})$ & $151 \pm 86$ & $137 \pm 73$ & $168 \pm 97$ & 0.019 \\
\hline $\begin{array}{l}\text { Creatinine } \\
(\mathrm{mg} / \mathrm{dl})\end{array}$ & $0.97 \pm 0.41$ & $0.9 \pm 0.28$ & $1.05 \pm 0.52$ & 0.021 \\
\hline $\begin{array}{l}\text { Total bilirubin } \\
(\mathrm{mg} / \mathrm{dl})\end{array}$ & $0.72 \pm 0.39$ & $0.75 \pm 0.38$ & $0.69 \pm 0.41$ & 0.302 \\
\hline $\begin{array}{l}\text { Serum albumin } \\
(\mathrm{g} / \mathrm{dl})\end{array}$ & $3.57 \pm 0.45$ & $3.83 \pm 0.24$ & $3.24 \pm 0.43$ & $<0.001$ \\
\hline $\begin{array}{l}\text { Total cholesterol } \\
(\mathrm{mg} / \mathrm{dl})\end{array}$ & $196 \pm 46$ & $212 \pm 42$ & $177 \pm 43$ & $<0.001$ \\
\hline $\begin{array}{l}\text { Triglycerides } \\
(\mathrm{mg} / \mathrm{dl})\end{array}$ & $176 \pm 92$ & $188 \pm 84$ & $161 \pm 99$ & 0.050 \\
\hline $\mathrm{LDL}(\mathrm{mg} / \mathrm{dl})$ & $120 \pm 40$ & $132 \pm 38$ & $107 \pm 37$ & $<0.001$ \\
\hline HDL (mg/dl) & $41 \pm 12$ & $43 \pm 12$ & $39 \pm 12$ & 0.014 \\
\hline INR & $1.06 \pm 0.34$ & $1.07 \pm 0.36$ & $1.05 \pm 0.32$ & 0.770 \\
\hline TSH $(\mu \mathrm{IU} / \mathrm{mL})$ & $1.02(0.83-1.66)$ & $1.26(0.92-1.94)$ & $0.97(0.7-1.25)$ & $<0.001$ \\
\hline CRP (mg/dl) & $0.8(0.4-1.3)$ & $0.6(0.3-1)$ & $1(0.5-2.1)$ & $<0.001$ \\
\hline
\end{tabular}

Data are expressed as mean \pm SD or median (interquartile range) as appropriate. TSH: Thyroid stimulating hormone, CRP: C-reactive protein, LDL: Low-density lipoprotein, HDL: High-density lipoprotein, INR: International normalized ratio

Table 4. Predictors of MACE in univariate and multivariate logistic regression analysis

\begin{tabular}{lllll}
\hline Parameter & Univariate analysis & \multicolumn{3}{l}{ Multivariate analysis } \\
\hline & OR $(95 \% \mathrm{CI})$ & $p$ & OR $(95 \% \mathrm{CI})$ & $p$ \\
Age & $1.061(1.020-1.103)$ & 0.003 & $1.058(1.013-1.105)$ & 0.011 \\
Hypertension & $1.800(0.763-4.245)$ & 0.179 & $2.187(0.783-6.109)$ & 0.135 \\
Diabetes mellitus & $0.960(0.471-1.958)$ & 0.912 & $1.155(0.505-2.645)$ & 0.733 \\
Smoker & $1.407(0.706-2.802)$ & 0.332 & $2.203(0.992-4.890)$ & 0.052 \\
Statins & $2.529(0.302-21.16)$ & 0.392 & $2.802(0.293-27.216)$ & 0.370 \\
Rhythm & $0.810(0.162-4.051)$ & 0.797 & $0.809(0.140-4.666)$ & 0.813
\end{tabular}




\begin{tabular}{lllll}
\hline Parameter & Univariate analysis & & Multivariate analysis & \\
\hline LDL & $1(0.991-1.008)$ & 0.933 & $1.007(0.997-1.018)$ & 0.175 \\
Beta blocker & $1.240(0.579-2.658)$ & 0.580 & $0.890(0.376-2.108)$ & 0.791 \\
NLR & $1.109(0.977-1.258)$ & 0.108 & $1.051(0.913-1.209)$ & 0.489 \\
PNI & $0.915(0.864-0.970)$ & 0.003 & $1.001(0.915-1.095)$ & 0.987 \\
CONUT score & $1.134(1.130-1.590)$ & 0.001 & $1.383(1.017-1.881)$ & 0.039 \\
\hline
\end{tabular}

MACE: Major adverse cardiac events, OR: Odds ratio, CI: Confident interval, LDL: Low-density lipoprotein, NLR: Neutrophil-to-lymphocyte ratio, PNI: Prognostic nutritional index

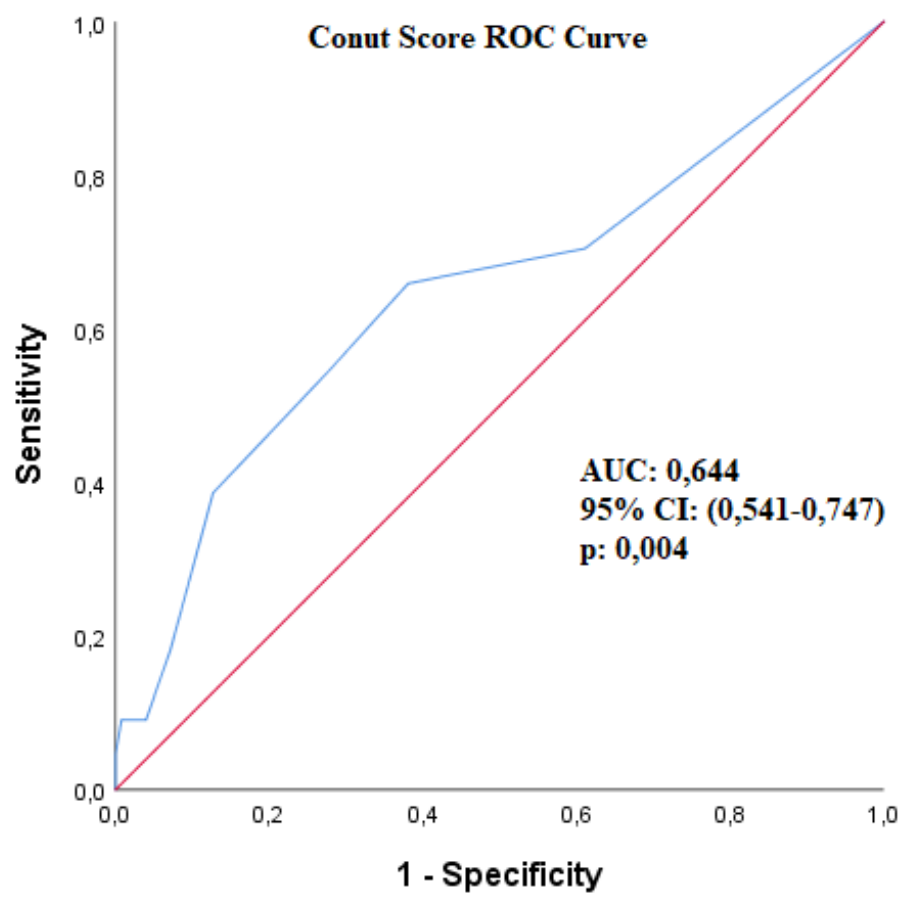

Figure 1. Receiver-operating characteristic (ROC) curve indicating the ability of CONUT score to predict MACE in patients with carotid artery stenting. AUC: Area under the curve, CI: Confident interval 


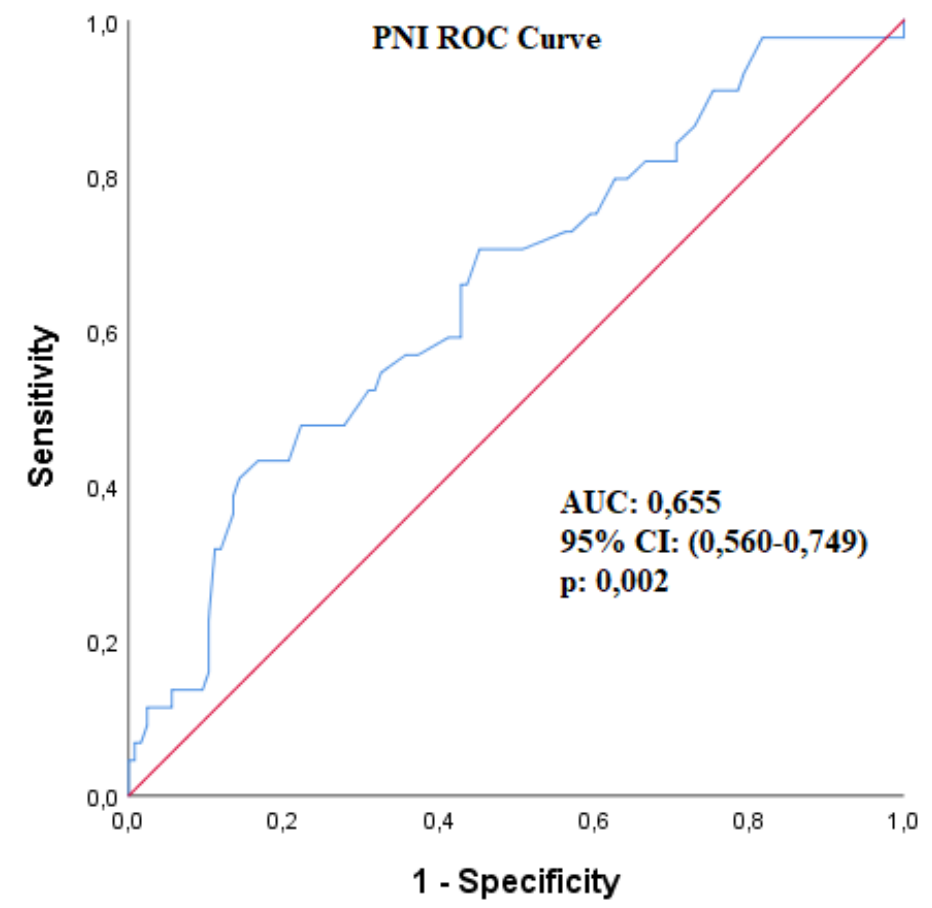

Figure 2. Receiver-operating characteristic (ROC) curve indicating the ability of prognostic nutritional index (PNI) to predict MACE in patients with carotid artery stenting. AUC: Area under the curve, CI: Confident interval

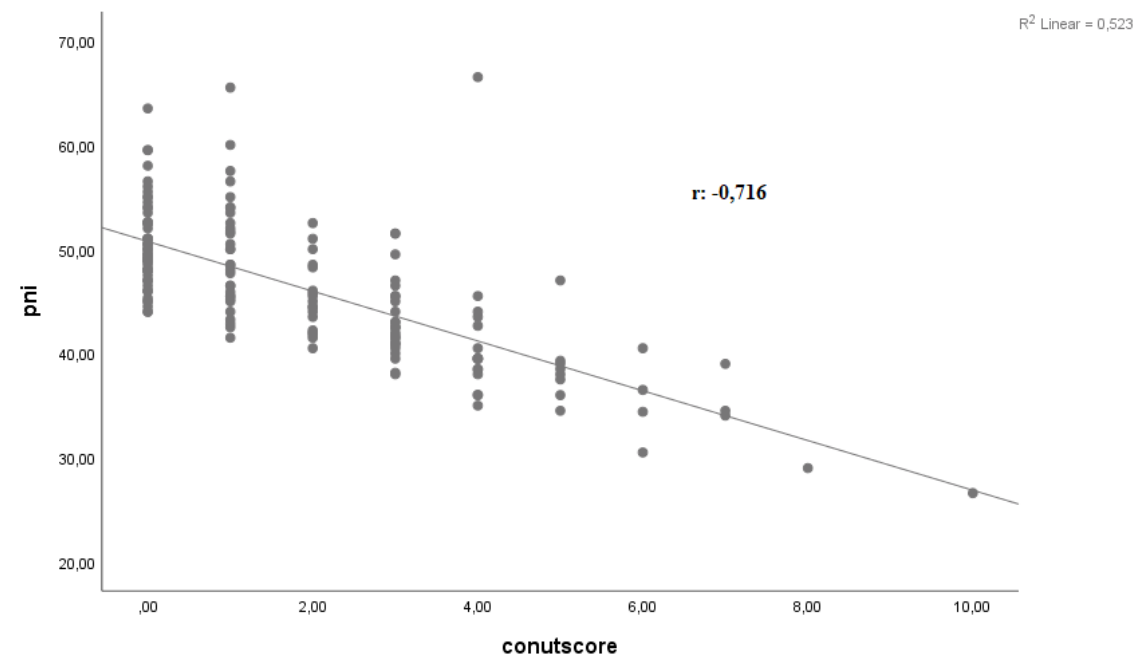

Figure 3. Correlation analysis of CONUT score with PNI 


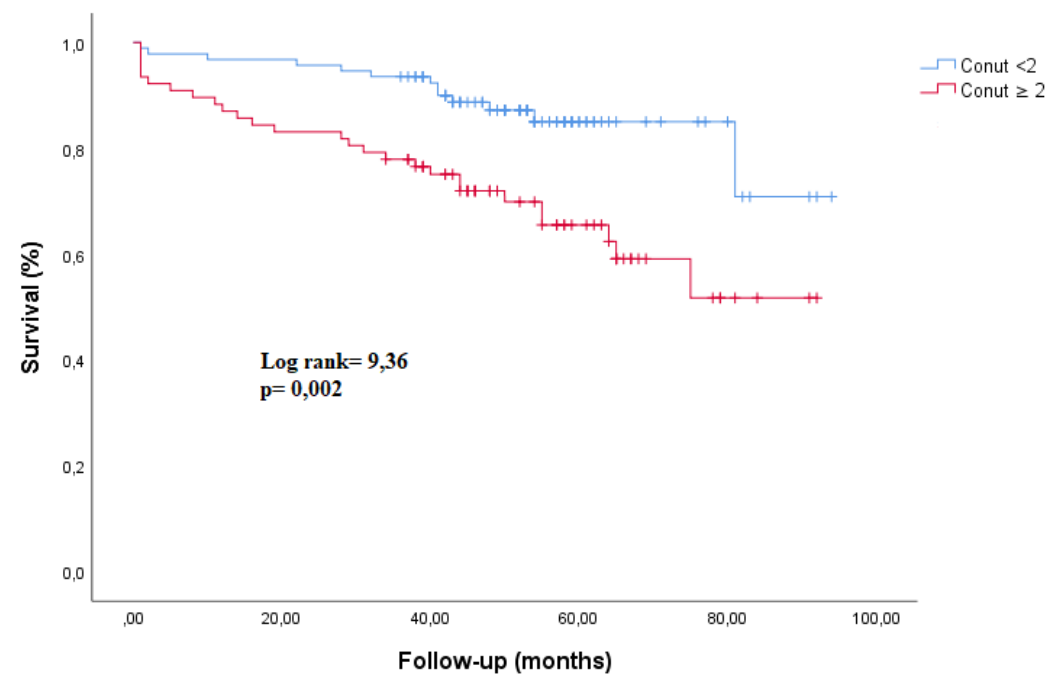

Figure 4. Kaplan-Meier survival analysis for CONUT score. During long-term follow-up period (median, 50 months), patients group with CONUT [?]2 had significantly worse survival than patients group with CONUT $<2(p=0.002)$. Mean survival period for CONUT $<2$ and CONUT [?]2 was $(83.001 \pm 2.946$ and $65.965 \pm 4.048$ months, respectively) $(p=0.002)$.

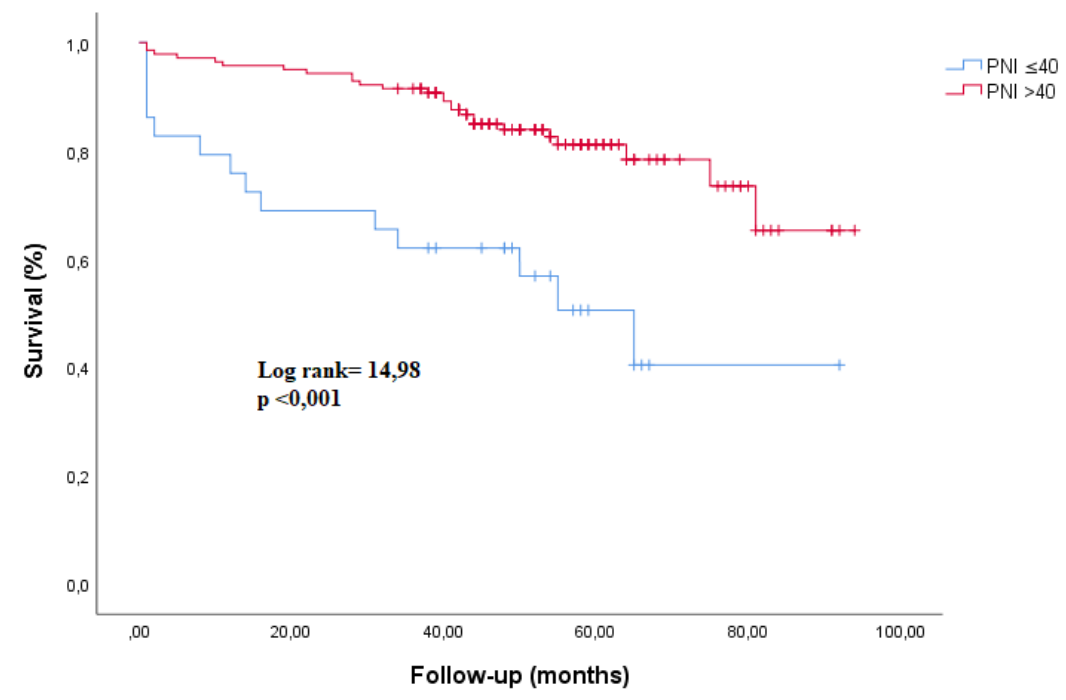

Figure 5. Kaplan-Meier survival analysis for PNI. During long-term follow-up period (median, 50 months), patients group with PNI [?]40 had significantly worse survival than patients with PNI $>40(p<0.001)$. Mean survival time for PNI [?]40 and PNI $>40$ was $54.033 \pm 7.277$ and $79.521 \pm 2.607$, respectively $)(p<0.001)$. 

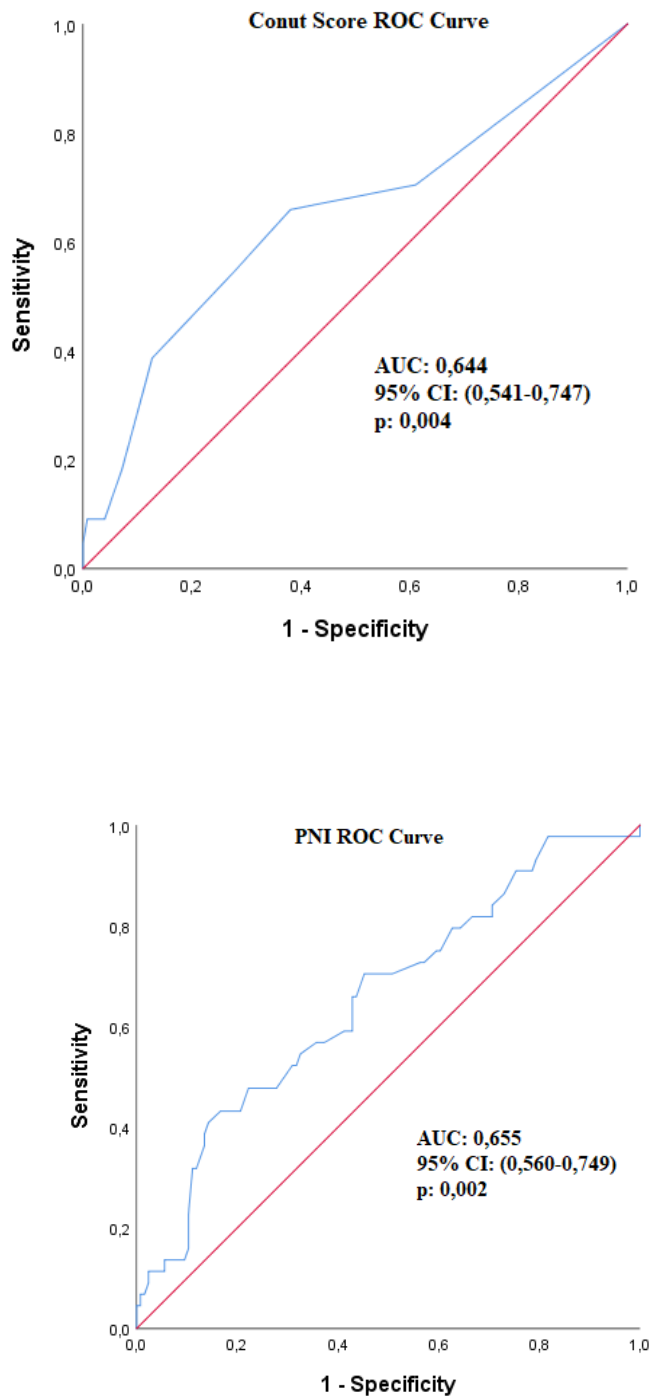

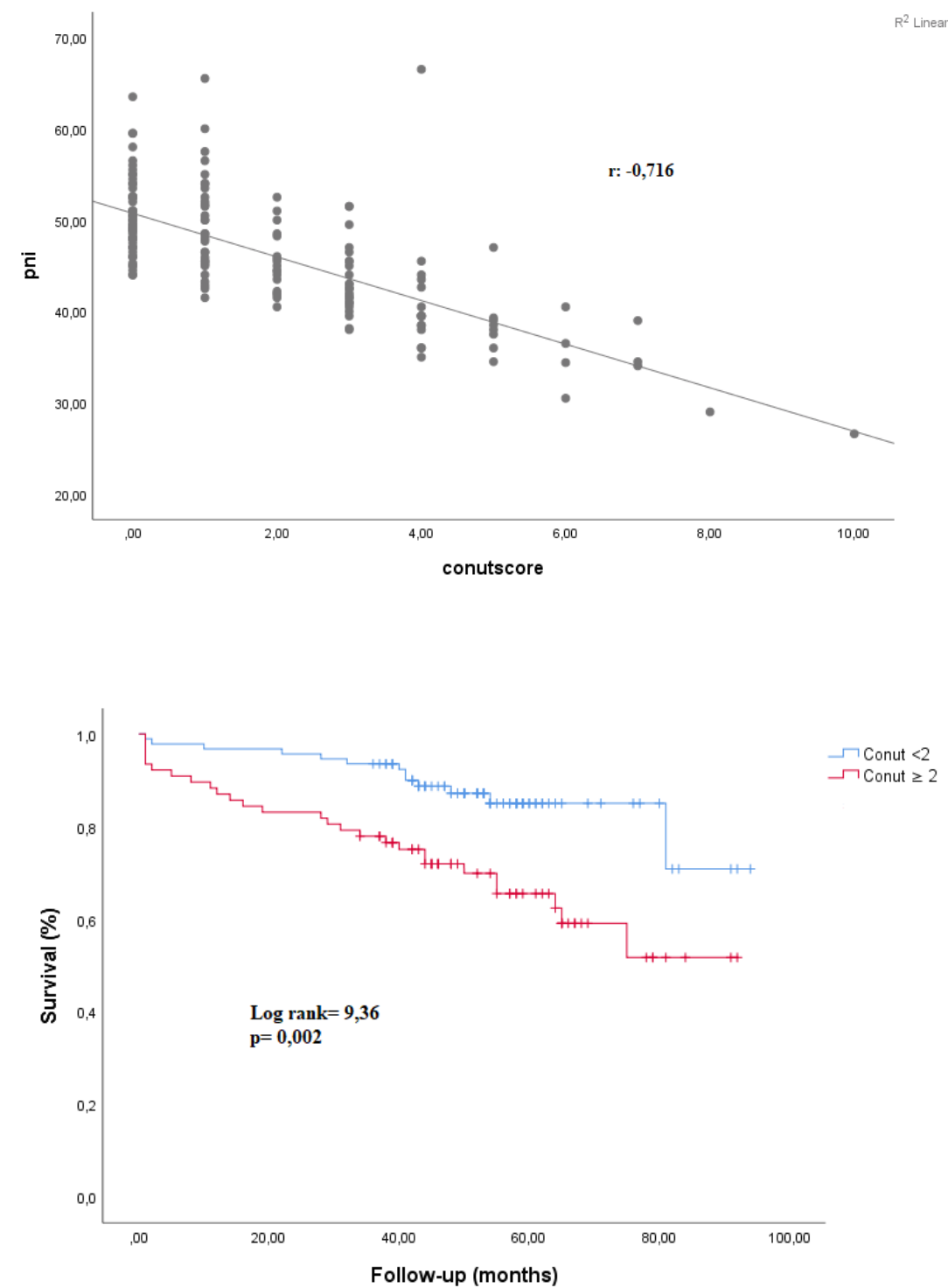


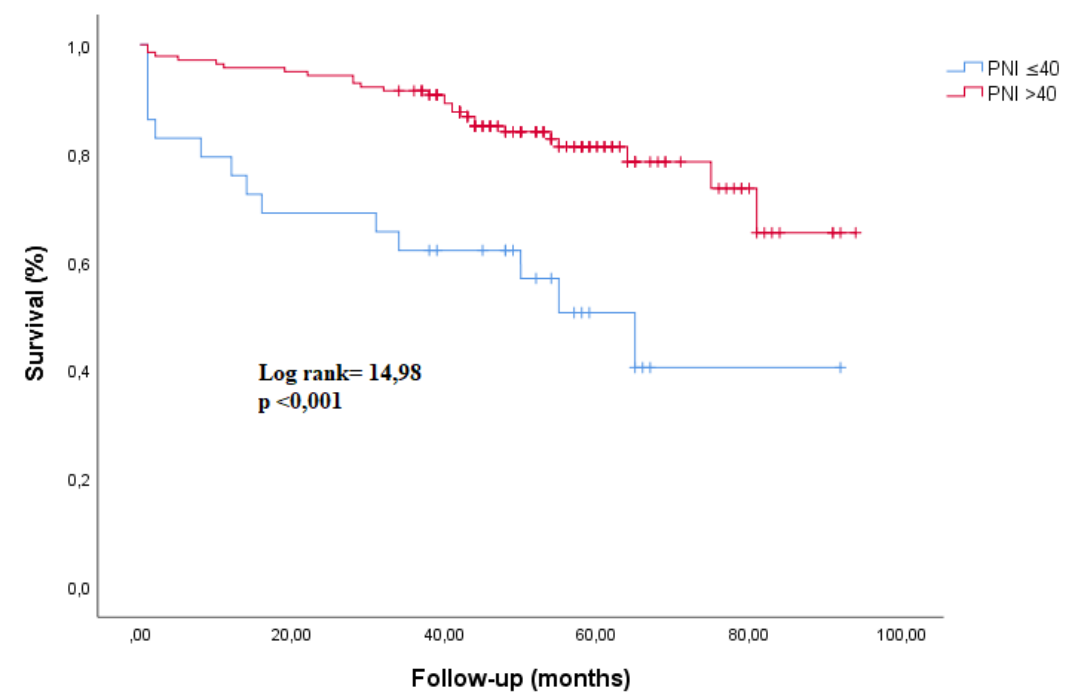

\section{Hosted file}

Tables.docx available at https://authorea.com/users/410353/articles/526949-impact-ofnutritional-assessment-on-long-term-outcomes-in-patients-with-carotid-artery-stenting 